\title{
The Experiences of Black Faculty at Predominately White Institutions in Minnesota
}

\author{
Egypt Grandison, Gabriel Warren, David Frison \\ Bemidji State University, Bemidji, USA \\ Email: Egypt.grandison@bemidjistate.edu, Gabriel.warren@bemidjistate.edu, David.frison@bemidjistate.edu
}

How to cite this paper: Grandison, E., Warren, G., \& Frison, D. (2022). The Experiences of Black Faculty at Predominately White Institutions in Minnesota. Open Journal of Social Sciences, 10, 57-66. https://doi.org/10.4236/jss.2022.103004

Received: February 1, 2022

Accepted: March 4, 2022

Published: March 7, 2022

Copyright (c) 2022 by author(s) and Scientific Research Publishing Inc. This work is licensed under the Creative Commons Attribution International License (CC BY 4.0).

http://creativecommons.org/licenses/by/4.0/ (c) (i) Open Access

\begin{abstract}
The body of research focused on the recruitment and retention of black faculty members at predominately white institutions (PWIs) has continued to evolve throughout the years. Colleges and universities have found it challenging to not only recruit black faculty, for a variety of reasons, ranging from the location of the institution to the faculty member not finding a sense of belonging and community. In this paper, we conducted a case study of three black faculty members who are in tenure track positions at a PWI in northern Minnesota. We interviewed each faculty member to gain a deeper understanding of their experiences being at a PWI, and identify what types of resources, university, and community support they need that could aid in their retention. The results from this study can be used by university administrators to aid in having discussions pertaining to the recruiting and retention of black faculty at their institution, and how it can align with the institution's diversity, equity, and inclusion goals.
\end{abstract}

\section{Keywords}

Faculty of Color, Recruitment, Retention, Higher Education, Professional Development, Enrollment

\section{Background}

Throughout the years, predominately white colleges and universities have had to solve the problem of finding ways to recruit and retain black faculty members. This problem has been noted in the many peer-reviewed articles in the existing body of knowledge on the topic of the black faculty experience at predominately white institutions (PWIs). According to the National Center for Education Statistics, in fall 2017, out of the 1.5 million faculty in degree-granting postsecondary institutions, less than $3 \%$ of the full-time faculty were black males or black 
females. The low number of black faculty at PWIs has tremendous impact on the black student population at institutions, as the students might not be able to identify role-models and mentors that look like them or come from communities that are similar to how the students grew up (Edwards \& Ross, 2018).

Therefore, the issue of not having an adequate amount of black faculty members to teach at these institutions can also speak to the retention efforts of black students. In most cases, the black student population percentage was on average, twice as high as the black faculty percentages at the PWIs, which means the black faculty could find themselves not only engaging in activities that could lead them to tenure, but also be engaged in excessive service activities that non-black faculty might not have to do (mentoring black students, serving as an advisor to several student groups, being a role model, and offering additional support activities to black students) (Jayakumar, Howard, Allen, \& Han, 2009). Not only does engaging in excessive activities lead to feelings of black faculty feeling overworked and burnout, it speaks to the overall experiences of black faculty at PWIs, which is the focus of our research in this article. We believe if universities can understand the experiences of black faculty at PWIs, it could aid in successful efforts to recruit and retain black faculty in tenure track positions at PWIs. The problem our research has identified is the lack of black faculty at PWIs has a direct impact on the recruitment and retention of black student enrollment numbers. We know that students have a desire to engage with teachers who look like them, share similar life experiences as them, and can act as a mentor to them. Our objective with this research is to provide insight to administrators at PWIs on ways they can engage in recruitment and retention efforts of black faculty, as part of the university or college's overall enrollment strategy. Taking this step could have a positive benefit to the overall revenue colleges receive.

\section{Literature Review}

Higher education professionals and faculty do not reflect the overall population of undergraduates or the shifting demographics in the United States. Fewer than a quarter of faculty members are nonwhite, and only 6 percent are Black, according to 2017 data from the National Center for Education Statistics, or NCES. The data show that 14 percent of undergraduates are Black, more than double the percentage of Black faculty members and still greater than the percentage of Black professional employees. More than 13 percent of the United States population is Black, according to U.S. Census Bureau estimates from 2019.

Cheryl Fields article "A Morale Dilemma: Black Professors in on White Campuses" discusses the challenges faced by black faculty at predominantly white universities. Fields (1996) states the challenges black faculty face are tense relations with white professors, questioning of one's credentials, lack of respect from non-black students, and a feeling of cultural, social, and professional isolation. According to Louis et al. (2016), black faculty members work on committees that handle minority issues and diversity programs on their campuses and 
provide more advising, mentoring, and service-oriented responsibilities for underrepresented students. Because Black faculty members are underrepresented, students of color are more likely to seek advice from them. Given the ethnic and racial imbalances within higher education and society, black faculty members realize and accept their societal duty (Cooke and Odejimi, 2021). However, institutions that are successful in recruiting and retaining African American faculty members do a far better job recruiting, enrolling, and graduating African Americans students than do those with few or no African American faculty members (Blackwell, 1981). Brown (2020) suggests as a black professors who are teaching majority White students, your classroom interaction can be varied. Some students are enthusiastic, well prepared, and engaged. They ask questions, there seems to be a sense of appreciation for your presence, and they tend not to bristle when encouraged by you to expound on a response or when they are told that their response is not correct. Some, however, will use the excuse that they do not participate in class because you always say that they are wrong. This tends to be the deflection from taking any responsibility for the lack of academic preparation or that more focused effort may be required. And then, there are students who seem to view you as an enigma. Granted, there will be some White students who have never been taught by a Black professor or a Black teacher. That be said, some White students think the intellectual capacity of Blacks, particularly Black Americans, is inferior to that of Whites and, as a Black person in academia, you are not qualified, no matter your credentials, expertise and years of experience, to teach a White person.

According to Killough, Kilough, Walker, \& Williams (2017), rising evidence suggests that institutions must be mindful of the range of reactions Black professors express and repress in response to difficult professional environments. The absence of Black faculty from the rolls of PWI's could appear to suggest that some environments may be aversived not only to recruitment but also to retention of Black faculty. While all faculty members must balance campus obligations with responsibility to their research agendas and professional progress, Black professors (and professors of color) tend to incorporate racial uplift in their work and carry larger service loads than their white counterparts (Griffin and Reddick, 2011). In addition, networking in higher education is difficult for many people, but the relatively few Black faces on many campuses make it especially tough for young Black faculty and staff members to find mentors (Whitford, 2020). Another feature of the black faculty experience in PWI's is a lack of good mentorship, which can be an obstacle to retention (Zambrana et al., 2015). Black faculty often feel mistreated in being "the onlys" or "very few" in their departments, colleges, universities, and they often find themselves working under the radar (Pittman, 2012). On largely white campuses, black faculty are regularly reminded of their race in ways that their white counterparts are not. That being said, because of their color, culture, or ethnic origin, an organization's collective failure is to give acceptable and competent service to people. It can be observed or discovered in inadvertent bias, ignorance, thoughtlessness, and racist stereo- 
types that disadvantage minority ethnic populations (Udah, 2017). Institutions have to promote an approach centered around academic mentorship, professional development, opportunities for tenure, promotion, and retention.

According to Flaherty (2020), black professors are overrepresented among non-tenure-track instructors in academia. They are both overrepresented and underrepresented in the sciences in lower-paying disciplines. Institutions typically consider private staff tenure decisions, but anecdotal and observational evidence indicate that black professors face challenges that their white counterparts may not face in advancing their professions. Institutions often espouse valuing diversity and believing in the importance of recruiting and retaining racially diverse faculty; yet, diversity is not reflected in equitable proportions, particularly within the most prestigious positions within the academy. Moreover, everyone benefits from exposure to diverse perspectives in the classroom and when faculty are diverse, students receive the type of education that prepares them for effective leadership and citizenship in a diverse democracy. The experience of Black faculty is one of many factors that can contribute to a poor campus climate for marginalized students (Kelly, Gayles, \& Williams, 2017). It is essential for higher education to be more creative in recruiting and retaining black faculty. Black faculty members sometime have experiences that are damaging negative, due to systemic isms and fears (Griffin, Pifer, Humphrey, \& Hazelwood, 2011).

Cornel West's 1993 article “The Dilemma of the Black Intellectual 13”. Above all, while it is important to discern how Black faculty at predominantly white institutions feel about their working relationships with colleagues and with the school as well as the emotional labor that must be performed in the "extra work" they are committed to like mentoring and counseling students, it is also vital to determine how Black professors feel about their primary role as scholars within the academy, and if they believe their primary role within the academy is as a scholar. What West calls for are Black intellectuals who 1) know the bourgeois system of academia, 2) maintain a commitment to revolutionary scholarship that has political consequences for the Black community, and 3) produce their work with a level of critical analysis that questions "truths" and the basic systems of knowledge and power in society. Researchers suggest that Black professors use very purposeful actions within the classroom to project confidence, credibility, knowledge, and other desired characteristics.

Black professors often feel intolerable at white institutes once they're hired by them. Black professors feel unseen or hyper-visible at white institutions. Often hired as "eye candy", they're then either overburdened or looked over strongly, both of which may cause them to seek employment elsewhere (Krupnick, 2018).

\section{Findings/Context/Participants}

The participants included three African Americans; one woman and two men. They all work in the same higher education field; a predominantly White uni- 
versity (PWI) in Minnesota Midwest area. A questionnaire was used to conduct the findings. All names and places have been replaced with pseudonyms.

The participants agreed to share their stories regarding experiences as a black professor at a predominately white University in Minnesota. The participants were interviewed through a one-hour open panel discussion, where 10 questions were asked. Four themes emerged that highlighted the participants experiences that they believe PWI's could focus more on when it comes to retaining black faulty; Professional development, mentorship, acceptance, and black student representation.

What would support look like for you as a black faculty member at a Predominately White University (PWI)?

All three participates' responses as to what support looks like to them were as followed; Feeling valued, acceptance, professional development, mentorship, showing interest in his or her experiences, and work on retention.

Based on the statistics discussed previously, how do you feel, knowing that you are a part of such a small group on campus and in the greater community of higher education?

Participants shared their experiences of self-imposed pressure due to fact of such a small group of blacks in higher education. Also, fear of making mistakes, competition amongst other non-black faculty, and having to work extra hard to be two steps ahead or better than the next person.

How important to you is having other black faculty members on campus with? Why?

Participants shared that it is important for students to see themselves when entering the classrooms. Students need to know that there is someone who shares their experiences and offer a safe place to talk, learn, and feel like a regular student. Participants shared that their students like having role models that give them a sense of comfort. Because the students are the main priority, it is imperative that they have enough black faculty professors to help.

What is one challenge you have faced being a black professor at a PWI?

Participants shared similar experiences such as having to prove oneself to both faculty and students, when it comes to the level of their education. In addition, people being surprised that you are a professor in higher education.

What are a few ideas university administration at PWI's can work to retain black faculty members?

Participates agreed that University Administration should seek out other Institutes who have done a successful job with retaining black faculty. Find out their strategy and use it as a foundation to help make retaining black faculty better. Ask your black faculty for their input, and do not be afraid to make changes when necessary.

\section{Method}

This study is used the Heuristic model to conduct its analysis of the research participants. The Heuristic research model was developed over a period of sev- 
eral years by researcher Clark Moustakas (Moustakas, 1994). Heuristic Research Model allows the participants as well as the audience to share and grow in self-awareness through the lived experiences of the participants (Moustakas, 1994). In this study, the audience served as the researching body as the audience was able to question the participants about their lived experiences. The participants allowed the audience to share in their lived experience at a predominately white institution. Three participants two black males and one black female shared what it like living and working at a predominately white institution. The audience grows with the development and in revelation of self as the participant shared lived experiences (Moustakas, 1994). A panel discussion involving three black panelists was conducted in a large group setting. Each panelist was asked the same set of questions and was given a chance to respond. Each panelist then shared their lived experience of what it is like being a black faculty in a predominately white institution.

Purposeful sampling is used in qualitative study to help understand a phenomenon. Here the researcher selects a sample not randomly but based on the specific need of the study (Creswell, 2005). To understand what it is like to be a black faculty working at a predominately white institution black faculty participants were purposefully targeted. Three black faculty members were purposefully targeted and purposefully selected to participate on question and answer panel.

Because qualitative studies do not require that the sample size be large to achieve the research objectives; qualitative studies lose its generalization ability (Bornstein, Jager, \& Putnick, 2013). In other words, this study is particular to this university and to the experiences of the black faculty that are participating in the panel. Generalization is granted based on the assumption that black faculty working at other predominantly white universities share similar experiences.

Homogeneous Sampling is used when research participants possess similar characteristics or defined characteristics (Bornstein et al., 2013). According to the definition of homogeneity the sample must be uniform at every level without any visible differences (Bornstein et al., 2013). In this study the homogeneity socio-demographic element was that all participants were black tenure-tracked faculty. Using this as defining socio-demographic characteristics participate in the study that were 1) black, 2) member of faculty, and 3) who have not obtained full-tenure status but were on a tenure-tracked probational trail allowed the panel to reach its research objectives.

However, the study was not purely homogeneous if you add the socio-demographic element gender as a subgroup. The panel was comprised of two male participants and one female participant. Had all participants been male or all female then the study would have achieved homogeneity. That is until you added another socio-demographic subgroup, for instance age, or social status would have added another dimension and another barrier to overcome to achieve homogeneity. The disadvantages of not having a purely homogeneous subgroup on the panel were that noise base on gender entered into the study. The advantage 
of not having a purely homogeneous sample was that the noise base on gender allowed for a difference and sometimes deeper perspective. For instance, when questions were asked based on personal experience the experience varied depending on whether the respondent was male or female. In sum achieving purely homogeneity diminishes each time a socio-demographic subgroup entered, but the revelations that were reveled enhanced the conversation.

\section{Research Recommendations \& Implications}

The results of this research were quite alarming, but not surprising as it proves the need for change and methods of more equitable support for black faculty at predominantly white institutions. This study showed that biases towards black faculty still needs to be addressed and an institution's attempt at increasing diversity also need to go beyond simply hiring more black faculty. Not only do black faculty that are hired into a PWI face many challenges but also face challenges that extend beyond the institutions. Black faculty are more likely to be racially profiled by law enforcement in predominately white communities. Black faculty suffer from isolation both at work and in the community from lack of people to talk with. The Black faculty feel immense pressure not only to overperform but also an unease of pressure from the community especially when social unrest issues arises both locally and nationally. Black faculty are often forgotten when it comes to mentorship and career pathways.

What can PWI do to recruit and retain black faculty? First, they can start by making the institution more welcoming to black faculty. One suggestion is to offer campus tours for new faculty in all aspects especially for black faculty. No faculty member wants to wander aimlessly around campus looking for their office, classroom, or place to eat, especially not within the black faculty who will be profiled by campus security. Secondly, introduce black faculty to administration, staff, faculty, and campus security during onboarding of new employees. This will help black faculty not appear as a vagrant that is wandering campus. Third, black faculty can serve as resources to recruit other minorities and black faculty. Black faculty can tap into their network of black qualified candidates to fill vacant faculty positions. PWI can serve as a resource bank for new black faculty by offering help with finding housing, helping black faculty maneuver with state and local municipals as they get setup in their new community such as the DMV. PWI can develop ways for black faculty to voice their concerns with administration by creating ERG or Affinity Groups tailored for black faculty. They can also provide mentors to black faculty and career path planning.

In addition, PWI must support "causes" surrounding black faculty that are deemed important or make clear its views on social justice and societal unrest when these issues occur. Black faculty already are out-numbered, marginalized, and made to feel as token representators for the black community. Adequate steps must be taken to ensure that black faculty feel respected and that their voices matter and hear when these issues arise. Black faculty are looked to by the PWI when it comes to planning and hosting events around national holidays, but these events are often forgotten when black faculty apply for tenure and 
promotion. PWI should offer special recognition when these events are performed thereby, the events can be remembered when linked to recognition awards.

PWI waste no time nor spare any expense when it comes to measuring and improving campus climate for students, but often forgotten in this equation is the campus climate results expressed by black faculty. Black faculty must be allowed to voice their concerns and when voiced these concerns must be taken seriously. PWI must take significant steps in improving its relationship with black faculty if it plans to continue to not only to recruit but retain black faculty. Black faculty must feel appreciated and valued in the space that they occupy and a path to obtain tenure and promotion must be made clear to black faculty.

\section{Conclusion}

Universities and colleges around the world have been faced with declining enrollment challenges for the last several years. Our research explored one strategy that administrators can consider as a part of the university's overall strategic enrollment plan. The recruitment and retention of black faculty members can serve as a key focal point for institutions who are seeking ways to solve the enrollment problem at their university. As an administrator for a PWI, our research provides findings that can be useful in discussions about the systems, policies, and procedures that may be currently setup by the institution that presents barriers so black faculty members can remain at their institutions. Having this discussion at the cabinet level of institutions could lead to changes in stated policies that would allow for the experiences of black faculty on the campuses of PWIs in Minnesota and beyond to be improved in a way that the improved recruitment and retention of black faculty can be modeled by other institutions. As the world is becoming more diverse, and students of color are being able to go to college, having faculty that can serve not only as subject matter experts, but also as mentors and role models, could go a long way in recruiting and retaining students of color. We know that students of color represent a relatively small population of the student bodies at PWIs across the United States, and this research can leader to greater discussions about how a recruiting and retention strategy of black faculty can fit into their university's strategic enrollment plan.

Based off of our findings, we identified that black faculty experiences on PWI campuses were not perceived as being ideal situations for long-term career growth. Some examples of the experiences shared include: the need for black faculty to find a sense of community and belonging at the institution where they choose to work, external resources needed from the community such as entertainment choices, places of worship, ethnic food selections, and places to receive hair care and appropriate styling methods. Additionally, black faculty teaching at PWIs experience cultural taxation, by being called upon to engage in services activities and committees focusing on diversity, equity, and inclusion, which does 
not typically happen at the same level as their white colleagues. By no way is our research exhaustive of the unique needs and support of all black faculty members who work at PWIs. However, our research highlights some of the complexities of recruiting and retaining black faculty members at PWIs and our hope is to provide another perspective for consideration as university search committees, HR professionals and administrators engage in conversations centered around how the recruitment and retention of black faculty members can be a strategic priority in the university's overall enrollment goals.

\section{Conflicts of Interest}

The authors declare no conflicts of interest regarding the publication of this paper.

\section{References}

Blackwell, J. E. (1981). Mainstreaming Outsider: The Production of Black Professionals. General Hall.

Bornstein, M. H., Jager, J., \& Putnick, D. L. (2013). Sampling in Developmental Science: Situations, Shortcoming, Solutions, and Standards. Developmental Review, 33, 357-370. https://doi.org/10.1016/j.dr.2013.08.003

Brown, R. M. (2020). The Black Professor at Historically White Colleges and Universities. Diverse Issues in Higher Education. https://diverseeducation.com/article/188896

Cooke, S. M., \& Odejimi, K. B. (2021). Examining Practices of Retaining Black Female Faculty and Staff in Independent Schools. Journal of Black Studies, 52, 202-219. https://doi.org/10.1177/0021934720967038

Creswell, J. (2005). Educational Research: Planning, Conducting, and Evaluating Quantitative and Qualitative Research (2nd ed.). Pearson Education.

Edwards, W. J., \& Ross, H. H. (2018). What Are They Saying? Black Faculty at Predominantly White Institutions of Higher Education. Journal of Human Behavior in the Social Environment, 28, 142-161. https://doi.org/10.1080/10911359.2017.1391731

Fields, C. D. (1996). A Morale Dilemma: Black Professors on White Campuses. Black Issues in Higher Education, 13, 22-28.

Flaherty, C. (2020). Scholars Talk about Being Black on Campus in 2020. https://www.insidehighered.com/news/2020/10/21/scholars-talk-about-being-black-ca $\underline{\text { mpus-2020 }}$

Griffin, K. A., \& Reddick, R. J. (2011). Surveillance and Sacrifice: Gender Differences in the Mentoring Patterns of Black Professors at Predominantly White Research Universities. American Educational Research Journal, 48, 1032-1057. https://doi.org/10.3102/0002831211405025

Griffin, K. A., Pifer, M., Humphrey, J., \& Hazelwood, A. (2011). (Re)Defining Departure: Exploring Black-Professors' Experiences with and Responses to Racism and Racial Climate. American Journal of Education, 117, 495-526. https://doi.org/10.1086/660756

Jayakumar, U. M., Howard, T. C., Allen, W. R., \& Han, J. C. (2009). Racial Privilege in the Professoriate: An Exploration of Campus Climate, Retention, and Satisfaction. The Journal of Higher Education, 80, 538-563. https://doi.org/10.1080/00221546.2009.11779031

Kelly, B. T., Gayles, J. G., \& Williams, C. D. (2017). Recruitment without Retention: A 
Critical Case of Black Faculty Unrest. Journal of Negro Education, 86, 305-317. https://doi.org/10.7709/jnegroeducation.86.3.0305

Killough, A., Kilough, E., Walker, E., \& Williams, O. (2017). Examining the Delicate Balance of Maintaining One's Blackness as a Black Professional on the Predominantly White Campus. Journal of Best Practices in Health Professions Diversity, 10, 81-110.

Krupnick, M. (2018). After College Promised to Increase It, Hiring of Black Faculty Declined.

https://hechingerreport.org/after-colleges-promised-to-increase-it-hiring-of-black-facu lty-declined

Louis, D. A., Rawls, G. J., Jackson-Smith, D., Chambers, G. A., Phillips, L. L., \& Louis, S. L. (2016). Listening to Our Voices: Experiences of Black Faculty at Predominantly White Research Universities with Microaggression. Journal of Black Studies, 47, 454-474.

https://doi.org/10.1177/0021934716632983

Moustakas, C. (1994). Phenomenological Research Methods. Sage Publications. https://doi.org/10.4135/9781412995658

Pittman, C. T. (2012). Racial Microaggressions: The Narratives of African-American Faculty at a Predominantly White University. The Journal of Negro Education, 81, 82-92. https://doi.org/10.7709/jnegroeducation.81.1.0082

Udah, H. (2017). Racial Hierarchy and the Global Black Experience of Racism. Open Journal of Social Sciences, 5, 137-148. https://doi.org/10.4236/jss.2017.53012

Whitford, E. (2020). Black Administrators Are Too Rare at the Top Ranks of Higher Education. It's Not Just a Pipeline Problem.

https://www.insidehighered.com/news/2020/10/28/black-administrators-are-too-rare-t op-ranks-higher-education-it\%E2\%80\%99s-not-just-pipeline?utm_source=Inside+Hig her+Ed\&utm_campaign=a2e5fdfb55-DNU_2020_COPY_02\&utm_medium=email\&ut $\underline{\mathrm{m} \_ \text {term=0_1fcbc04421-a2e5fdfb55-197433889\&mc_cid=a2e5fdfb55\&mc_eid=16878a3 }}$ $\underline{7 \mathrm{eb}}$

Zambrana, R. E., Ray, R., Espino, M. M., Castro, C., Douthirt Cohen, B., \& Eliason, J. (2015). "Don't Leave Us Behind": The Importance of Mentoring for Underrepresented Minority Faculty. American Educational Research Journal, 52, 40-72.

https://doi.org/10.3102/0002831214563063 